\title{
O designer e a gráfica: parceria e informalidade
}

The designer and the printers: partnership and informality

\author{
AMINGER, Andrea Franco; Especialista; ESPM Rio \\ andrea.aminger@gmail.com \\ MIGLIARI, Mirella De Menezes; Doutora; ESPM Rio \\ migliari@espm.br
}

\section{Resumo}

O setor gráfico situa-se no final da cadeia produtiva de um projeto de design gráfico, estando diretamente relacionado com sua produção. Nesta simbiose profissional entre designer gráfico e fornecedor gráfico, a ausência de leis mais robustas deixam diversas brechas que propiciam uma relação permeada por informalidade, de um modo geral, nas pequenas empresas do setor no Brasil. Este artigo apresenta um estudo de caso de uma pequena gráfica, com o nome fictício de Navio Serigrafia, a qual situa-se no Estado do Rio de Janeiro, com inscrição no Simples Nacional. O estudo baseia-se no relatório Diagnósticos e Mapeamentos Setoriais: Retrato Setorial Gráfico e Editorial, desenvolvido pela Firjan (2017), e nas entrevistas realizadas com os sócios-proprietários desta empresa. Por fim avalia-se o impacto que tais informalidades e procedimentos poderão causar a ambas as áreas de atuação profissional envolvidas.

Palavras Chave: designer e gráfica; setor gráfico; informalidade.

\begin{abstract}
The graphic sector is located at the end of the productive chain of a graphic design project, being directly related to its production. In this professional symbiosis between graphic designer and graphic supplier, the absence of more robust laws leaves several gaps that provide a relationship permeated by informality, usually in the small companies of the sector in Brazil. This article presents a case study of a small graphic, with the fictitious name of Navio Serigrafia, located in the State of Rio de Janeiro, within scription in Simples Nacional. The study is based on the report Diagnostic and Sector Mappings: Graphic Portrait and Editorial of the Sector, developed by Firjan (2017), and in the interviews with the owners of this company. Eventually, the impact that such informality and procedures can have on both areas of professional activity involved is evaluated.
\end{abstract}

Keywords: designer and printers; printing industry; informality. 


\section{Introdução}

Com o intuito de proteger a empresa do setor gráfico que foi utilizada como objeto de estudo e exemplo relatado nesse artigo, todas as informações reais foram suprimidas e modificadas, tais como o real nome (razão social), endereço, e todos os demais dados referentes ao seu registro na lei brasileira. Portanto, esta empresa será denominada neste artigo como Navio Serigrafia, nome fictício. Apenas as informações relacionadas ao tipo de serviço que essa gráfica oferece - a produção utilizando a técnica de impressão por serigrafia - e também sua localidade, no estado do Rio de Janeiro, são condizentes com a realidade dos fatos.

Trata-se de pesquisa qualitativa, para a qual todos os fatos relatados ao longo desse artigo sobre a gráfica Navio Serigrafia foram extraídos através de técnicas de pesquisa de campo, como visitas ao local e entrevista em profundidade com os próprios donos da empresa. Sendo assim, foram colhidos dados primários para que se pudesse comprovar e legitimar as informações apresentadas.

Este artigo inicia-se com uma breve apresentação do panorama gráfico do Estado do Rio de Janeiro, para que se entenda como essa empresa se posiciona na realidade desse setor e Estado.

Em seguida será abordada a relação da gráfica Navio Serigrafia com as leis brasileiras, a partir de seu registro no Cadastro Nacional da Pessoa Jurídica - CNPJ - como também a ausência de registro de sua marca no INPI - Instituto Nacional de Propriedade Industrial. Por fim, é abordado como essa gráfica elabora seus contratos, orçamentos e notas fiscais.

A relação da gráfica Navio Serigrafia com a economia criativa é abordada ao final, para que que se tenha um retrato fiel sobre como ela, e suas semelhantes, se mantêm no ambíguo mundo da informalidade.

\section{Panorama gráfico do Estado do Rio de Janeiro}

A fim de que se compreenda a posição que a gráfica Navio Serigrafia ocupa no Estado do Rio de Janeiro, foram levantados alguns pontos da publicação Diagnósticos e Mapeamentos Setoriais: Retrato Setorial Gráfico e Editorial, desenvolvido pela Federação das Indústrias do Estado do Rio De Janeiro (Firjan), em 2017.

Esse estudo apresenta, além de outros pontos, a evolução do setor gráfico e o perfil das atividades econômicas que compõem esse segmento. Essas atividades foram divididas em quatro grandes segmentos, de maior afinidade entre si, de maneira a permitir a identificação das particularidades e diferenças de comportamentos entre eles.

Segue a lista das atividades econômicas que compõem cada um dos segmentos encontrados na publicação da Firjan (2017), de acordo com a Classificação Nacional de Atividades Econômicas CNAE Versão 2.0 (2017): 
ATIVIDADES DE IMPRESSÃO:

1811-3: Impressão de jornais, livros, revistas e outras publicações periódicas.

1812-1: Impressão de material de segurança.

1813-0: Impressão de materiais para outros usos.

SERVIÇOS DE PRÉ-IMPRESSÃO E ACABAMENTOS GRÁFICOS:

1821-1: Serviços de pré-impressão.

1822-9: Serviços de acabamentos gráficos.

ATIVIDADES DE EDIÇÃO:

5811-5: Edição de livros.

5812-3: Edição de jornais.

5813-1: Edição de revistas.

5819-1: Edição de cadastros, listas e de outros produtos gráficos.

EDIÇÃO INTEGRADA À IMPRESSÃO:

5821-2: Edição integrada à impressão de livros.

5822-1: Edição integrada à impressão de jornais.

5823-9: Edição integrada à impressão de revistas.

5829-8: Edição integrada à impressão de cadastros, listas e de outros produtos gráficos.

Fonte: Firjan, 2017.

A partir dos gráficos apresentados abaixo, na Figura 01, pode-se identificar a quantidade de empresas (1763) e empregos (17980) gerados no setor gráfico de acordo com dados publicados em 2017, e relativizar a importância deste setor para o Estado Fluminense. Também é possível avaliar como se apresenta a divisão das áreas deste setor, conforme Classificação Nacional de Atividades Econômicas da Firjan (2017). É nesse contexto que a gráfica Navio Serigrafia se enquadra. 
Figura 1 -Distribuição dos Estabelecimentos e Empregos da Indústria Gráfica e Editorial Fluminense

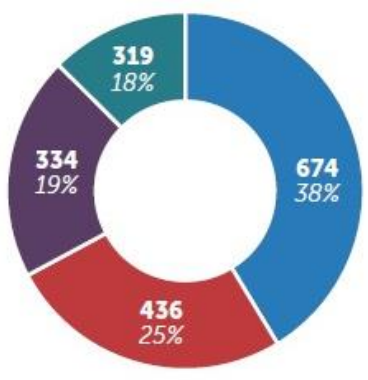

Estabelecimentos (2015)

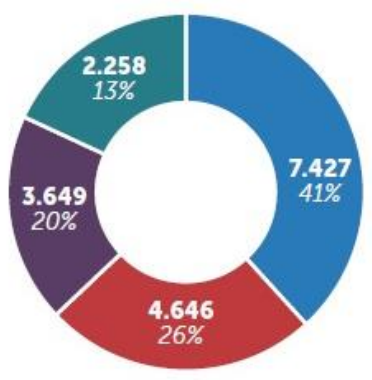

Empregados (2016)

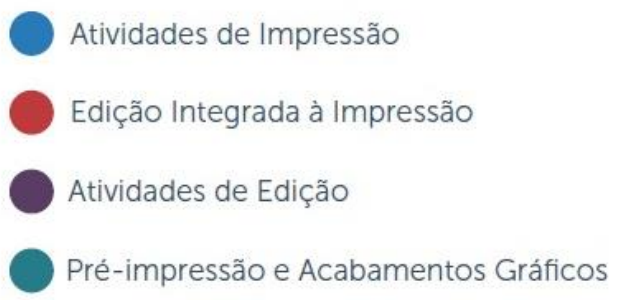

Pré-impressão e Acabamentos Gráficos

Fonte: Firjan, 2017.

Identificou-se também, a partir do Quadro 1, que não havia sido feito um estudo específico pela Firjan para diferenciação das gráficas no segmento Atividades de Impressão - pois neste segmento há atividades de impressão específicas e diferenciadas - e dessa maneira não foi possível estabelecer a quantidade de gráficas que se dedicam à impressão pela técnica de serigrafia no Estado do Rio de Janeiro. A partir da observação do Quadro 1, também é possível avaliar a ordem de grandeza deste sub segmento, no qual é apresentado a quantidade de ocupações como: Impressor de Serigrafia - são 326 contra 713 Impressores de Offset, e 208 Impressores Tipográficos. 


\begin{tabular}{|c|c|}
\hline Ocupações & 2016 \\
\hline Alimentador de Linha de Produção & 2.119 \\
\hline $\begin{array}{l}\text { Impressor de Offset } \\
\text { (Plano e Rotativo) }\end{array}$ & 713 \\
\hline Operador de Acabamento & 683 \\
\hline Jornalista & 399 \\
\hline Impressor (Serigrafia) & 326 \\
\hline Editor de Texto e Imagem & 253 \\
\hline Designer Gráfico & 249 \\
\hline Impressor de Corte e Vinco & 228 \\
\hline $\begin{array}{l}\text { Operador de Guilhotina } \\
\text { (Corte de Papel) }\end{array}$ & 209 \\
\hline Impressor Tipográfico & 208 \\
\hline
\end{tabular}

Fonte: Firjan, 2017.

\section{A relação da gráfica Navio Serigrafia com a legislação}

A fim de que se compreenda a posição que a gráfica Navio Serigrafia ocupa no Estado do Rio de Janeiro, serão apresentados alguns pontos da publicação Diagnósticos e Mapeamentos Setoriais: Retrato Setorial Gráfico e Editorial, desenvolvido pela Firjan (2017).

Para melhor entendimento sobre a importância desse registro, seguem as informações referentes ao Cadastro Nacional da Pessoa Jurídica (CNPJ), e compreendemos que esse cadastro compreende as informações cadastrais das entidades de interesse das administrações tributárias da União, dos Estados, do Distrito Federal e dos Municípios. A administração do CNPJ compete à Secretaria da Receita Federal do Brasil (RFB, 2014). 
Seguem também informações retiradas do site da empresa Magna Empresa Jurídica Júnior (2017), sobre a importância e necessidade desse cadastro.

O Cadastro Nacional da Pessoa Jurídica (CNPJ) é o registro de pessoas jurídicas em território nacional, realizado junto à Receita Federal. Este cadastro se dá através de um número único, geralmente formado por 14 números, sendo os 8 primeiros a identificação da pessoa jurídica, os 4 seguintes identificam o endereço e os 2 últimos servem como meio de verificação do CNPJ. Portanto, o CNPJ é a forma de identificar as pessoas jurídicas, contendo nele o nome da empresa, data de abertura, descrição da atividade econômica principal e secundária, natureza jurídica, endereço e situação cadastral.

O intuito principal é registrar uma pessoa jurídica, identificando-a e comprovando a existência legal da mesma. É através dela que a Receita Federal irá acompanhar o pagamento de tributos e obrigações em geral da pessoa jurídica. Juntamente com isto, o CNPJ pode ser utilizado para obter diversas informações detalhadas da pessoa jurídica em relação à Receita Federal e outros tipos de averiguações, como consultar se a pessoa jurídica tem processos judiciais ou dívidas atrasadas, (Magna Empresa Jurídica Júnior, 2017).

A análise da situação legal da empresa aqui citada teve início com o exame do nome registrado (razão social), o qual está inscrito no CNPJ dessa gráfica, e identificou-se que o seguinte nome foi indevidamente oficializado: MAVIO PRODUÇÕES SERIGRÁFICAS; ao invés do seu nome utilizado comercialmente, que é na realidade NAVIO PRODUÇÕES SERIGRÁFICAS.

Em entrevista com os donos da gráfica, a fim de apurar-se o motivo dessa alteração do nome, foi informado que certamente aconteceu um erro em algum momento do cadastro na Receita Federal, ou em alguma etapa de renovação de cadastro. Pode ter ocorrido por ocasião de uma mudança de endereço, pois a empresa já passou por mudança de endereço três vezes desde a sua fundação. Os entrevistados ainda comentaram que demoraram a identificar essa alteração indevida do nome. Nesse caso específico ocorreu uma alteração sutil de nome, pois somente trocaram uma letra, um $\mathrm{M}$ ao invés do $\mathrm{N}$, que seria o correto.

Em questionamento aos donos sobre a não solicitação de retificação desta alteração indevida do nome, eles comunicaram que para se corrigir este registro é necessário passar por todo um processo burocrático que envolve tempo e custos, mesmo tendo sido um erro causado pela própria Receita Federal. Os próprios donos são os únicos responsáveis por essa resolução. Por fim, atualmente alguns documentos da gráfica estão corretos, com a letra $\mathrm{N}$, e outros ainda com a letra M. Ambos funcionam conjuntamente sem maiores problemas, e não existe uma lei que determine que os proprietários da empresa devam corrigir esse documento. É possível constatar, diante deste relato, que se incorreu num erro que contribui para aumentar o teor de informalidade com que se lida com tais ocorrências.

Outra observação sobre o registro no CNPJ desta gráfica faz-se relevante, a qual relacionase com o código e descrição da atividade econômica principal da empresa. De acordo com o que se apresenta na Classificação Nacional de Atividades Econômicas - CNAE (2017), é esta atividade principal que virá a determinar o tipo de serviço que a empresa do setor gráfico poderá desempenhar. Em teoria, a empresa somente poderia executar os serviços e entregas que estão definidos neste campo (segmento). No caso específico da gráfica Navio Serigrafia, ela está enquadrada no segmento de Serviços de Pré-impressão. 
Vale apontar que serviços de pré-impressão também podem eventualmente ser entregues por esta empresa, mas que não é este o segmento que melhor define a natureza das atividades profissionais realizadas ali. Eles vão muito além da pré-impressão, e têm como principal atividade a impressão propriamente dita - processo esse que relaciona-se a diversas etapas, a saber: gravação de matrizes de impressão, a impressão propriamente dita, corte, vinco e diversos outros acabamentos. Desta forma, a empresa aqui estudada deveria estar classificada no seguinte segmento: "ATIVIDADES DE IMPRESSÃO: 1813-0: Impressão de materiais para outros usos".

Também em entrevista com os donos buscou-se entender o motivo pelo qual a empresa teria sido registrada no segmento de Serviços de Pré-impressão, e não no segmento cuja aderência é patente, qual seja: Atividades de Impressão. Foi informado por eles que, dentro das possibilidades de escolha que se mostravam, no momento do registro esta teria sido a descrição que mais se enquadrava e se adequava, não existindo nenhuma outra descrição mais específica, como por exemplo "processo de impressão serigráfico", o que teria sido bem mais aderente à realidade.

Faz-se premente confirmar essa informação no tópico que foi apresentado acima como Panorama Gráfico do Estado do Rio de Janeiro. Nas opções de atividades econômicas, segundo a Classificação Nacional de Atividades Econômicas (2017), observando-se os códigos referentes a atividades de impressão, não haveria nenhum código específico de Impressão em Serigrafia. Os donos comentaram que prefeririam que o código e a descrição da atividade deles estivessem de acordo com o que eles realmente fazem, mas na ocasião do registro, para ser possível o registro CNPJ dessa empresa, eles acabaram escolhendo o código mais possível, porém não ideal. No entanto, questiona-se aqui a autonomia do empresário para cadastrar sua empresa da forma que melhor entender ou mesmo aquela que escolher, seja por conveniência ou ignorância, não havendo nenhuma verificação por parte da Receita Federal quanto a esta aderência. Então, mais uma vez evidencia-se um fator que contribui para a informalidade. $E$, mais grave, distorce o painel quantitativo do setor.

Mais adiante na pesquisa, foram abordadas as necessidades de se preparar documentos, quais sejam: orçamentos, notas fiscais, contratos, solicitação de pagamento de sinal para o desenvolvimento dos trabalhos da gráfica, etc. Nesta etapa, mais uma vez ficou patente a falta de rigidez nos procedimentos, o que vem a aumentar o teor de informalidade. Em alguns casos, houve até mesmo a conivência dos clientes da gráfica.

Em relação aos orçamentos apresentados em geral pela gráfica Navio Serigrafia, pode-se dizer que não sejam apresentados valores muito altos (tendo em vista a concorrência e o valor absoluto), e caso aconteça inadimplência por parte de um cliente, o custo e o tempo dispendidos para se recorrer não compensaria, de acordo com depoimentos dos sócios do negócio. As despesas com advogados ou com um protesto viriam a ser muito superiores àquilo que foi perdido. Os donos mencionaram que "não vale a pena correr atrás da inadimplência contratual", mesmo porque nem mesmo a gráfica utiliza "um contrato sério".

Para se ter uma ideia da extensão dessa informalidade, e como os clientes também cooperam para mantê-la, há muita dificuldade para a gráfica Navio Serigrafia conseguir receber o pagamento do sinal de 50 \%, na aprovação de uma proposta. Esse procedimento de cobrança é muito comum em muitos acordos de prestação de serviços nesta área, e previstos em contratos. Mesmo assim, a gráfica Navio Serigrafia usualmente consegue receber o pagamento do sinal de $50 \%$, nos casos de produção de convite de casamento, devido à urgência do tempo de entrega. 
Porém, em demais trabalhos é comum que consiga receber até $30 \%$ do valor orçado na entrada, mas em muitos casos, principalmente quando o cliente já é conhecido e está retornando, não se consegue cobrar sinal de entrada algum. Ao questionar os donos da gráfica sobre o por quê dessa dificuldade, eles apontaram tratar-se de hábitos do mercado - inerentes à cultura dos clientes que trabalham com esse tipo de serviço - ou seja, mais uma incidência de atitude que fomenta a informalidade, e que tem muito a ver com a cultura brasileira do setor em geral.

Os sócios da gráfica ainda complementam, ao final da entrevista, com o seguinte depoimento: "essas necessidades e obrigações são para grandes empresas, nacionais e multinacionais, para as pequenas empresas como nós, isso é impossível".

Continua-se então a desvendar através da pesquisa realizada a soma de fatores que contribuem para o "mundo da informalidade", pois entende-se que não existe uma lei ou fiscalização que exija e cobre a regulamentação dos pontos apresentados acima, e a gráfica dá continuidade ao seu funcionamento sem grandes entraves.

\section{A marca Navio Serigrafia e seu registro no INPI}

A fim de que se compreenda a posição que a gráfica Navio Serigrafia ocupa no Estado do Rio de Janeiro, serão apresentados alguns pontos da publicação Diagnósticos e Mapeamentos Setoriais: Retrato Setorial Gráfico e Editorial, desenvolvido pela Firjan (2017).

Segundo a definição de marca, na cartilha do Instituto Nacional de Propriedade Intelectual (INPI) intitulada A Criação de Uma Marca, "Marca é um sinal visualmente perceptível capaz de distinguir os produtos ou serviços de uma empresa, principalmente, em relação a outros concorrentes".

(2013, Acesso em: 22 dez. 2017

Diante do que está sendo apresentado acima, faz-se mister apontar a importância de se fazer um registro de uma marca, pois uma marca deve ser identificada pelos seus consumidores, e legitimar a qualidade de seu trabalho/entrega. Os consumidores associam uma marca ao histórico da empresa, e dessa maneira, ao longo dos anos, os consumidores identificam como é feita a entrega dos produtos, como acontecem as promoções, as propagandas, e principalmente como essa empresa se distingue perante sua concorrência. Com o passar do tempo, as experiências proporcionadas por esta marca se fixarão na memória da sociedade, e virão a definir sua reputação.

Segundo a matéria A Importância do Registro de Marca para o Designer , matéria essa que apresenta uma entrevista feita pelo blog Designers Brasileiros com um escritório de advocacia especializado em propriedade intelectual, "no Brasil, de cada 100 marcas criadas, apenas 10 fazem registro de marca no Instituto Nacional de Propriedade Intelectual (INPI)." (Designers Brasileiros, 2017).

Ainda nesta mesma matéria, é apresentado um fato que deveria preocupar tanto o empresário quanto o profissional de design gráfico, mas na verdade não é isso que verdadeiramente acontece. Pode-se identificar no fato relatado uma displicência, como a que ocorreu referente ao registro da marca da gráfica Navio Serigrafia. O fato foi que a assinatura visual da marca da gráfica Navio Serigrafia - um logotipo - foi desenvolvida por um designer bastante conhecido no mercado carioca, há cerca de vinte anos atrás (os sócios não conseguiram precisar a data com exatidão), e até o momento presente eles nunca registraram a marca no INPI. Nota-se que tanto o designer que desenvolveu o logotipo, quantos os donos da marca, não estão preocupados com este registro 
formal. Os sócios da gráfica até consideram importante fazer esse registro, mas não estabelecem como uma prioridade diante de todos os afazeres do cotidiano, talvez também influenciados pelo fato de que não exista uma lei que obrigue as empresas a registrarem suas marcas.

$\mathrm{E}$, no caso do profissional de design gráfico contratado para desenvolver a referida assinatura da marca, o registro da marca é algo de suma importância, pois trata-se de uma proteção do seu trabalho. Pois, se não há registro, outra empresa qualquer poderá se apropriar dessa assinatura e nome e utilizá-los, não importando a autoria do trabalho se não se fizer o registro previamente. Desta forma, coloca-se em risco todo um trabalho e esforço entre designer e cliente para desenvolver uma marca original, única, e sua reputação.

Analisando o histórico da gráfica Navio Serigrafia, é notável que os seus principais clientes foram, desde o princípio, representados por designers gráficos. E assim, diante da questão da informalidade abordada neste artigo, e como a falta de registro da marca poderá prejudicar ulteriormente esses designers, a empresa em questão deveria efetuar o registro de sua marca nem que fosse por uma questão de estratégia perante o nicho de clientes que atende, a fim de reconhecer o mérito da profissão. Fica patente aqui que a informalidade pode ameaçar ambos os agentes desta cena: prestador de serviço e cliente.

\section{A gráfica Navio Serigrafia e a Economia criativa}

Segundo Reis (2007), e sua definição sobre Tipologias de Valor, compreende-se que uma empresa com o perfil da Navio Serigrafia pode ser enquadrada com empresa de valor histórico, pois segundo a autora, com o passar do tempo, os objetos passam a assumir um valor histórico.

Entende-se dessa maneira que a gráfica Navio Serigrafia mantém uma tradição, dando continuidade a um valor histórico, pois essa gráfica permanece até o momento oferecendo o tipo de processo de impressão permeográfico. Por outro lado, muitas das gráficas que se iniciaram nesse setor, migraram para uma tecnologia mais atualizada.

Contribui também para seu valor histórico o fato de nenhuma máquina utilizada na gráfica Navio Serigrafia ser automatizada. Todo o maquinário precisa ser operado à mão, ou seja, trata-se de tecnologia mecânica. Dessa maneira, pode-se traçar uma relação entre esses procedimentos mecânicos e o artesanato, pois em ambos os processos gera-se produtos feitos manualmente. Sendo assim, entende-se que os clientes que procuram essa gráfica valorizam uma tradição no setor de impressão. Portanto, forma-se um vínculo de cumplicidade entre cliente e fornecedor, a ponto também de se relevarem diversos procedimentos que viriam a formalizar esta relação.

No que diz respeito à maneira como a gráfica Navio Serigrafia atende seu cliente, no caso específico representado por profissionais de design gráfico, essa gráfica mantém um tratamento diferenciado. Ela se mantém próxima ao cliente, envolvendo-se desde a etapa do projeto gráfico, entendendo a importância que esse envolvimento tem para a qualidade do produto final. Sobre essa questão específica, os donos dessa gráfica entendem e abraçam essa questão, desenvolvendo um trabalho de interação com os designers gráficos, aproximando ao máximo o atendimento ao designer e a gráfica, dando suporte desde o início até o fim. Segundo entrevista feita com um dos sócios, segue o seu comentário: "acreditamos que as principais características da gráfica sejam: o envolvimento com o projeto gráfico e o entendimento da sua importância. Disso resulta a forma como atendemos o cliente". 
É possível confirmar essa valorização do elemento intangível, da proximidade com o cliente, segundo Bendassolli et al (2009), que apresenta a reconstrução mercadológica do consumidor como a segunda característica essencial do consumo no âmbito das indústrias criativas, e nesse processo se apresenta um novo regime da construção da subjetividade e da identidade pessoal. De qualquer forma, não se deve descartar os procedimentos formais que são inerentes à relação empresa e cliente, e que em última instância servem para resguardar ambos os lados.

Segundo a publicação do Instituto de Pesquisa Econômica Aplicada (Ipea), 1990, o mercado informal deve corresponder à maior parte da atividade econômica. Entendemos dessa maneira que muitas empresas brasileiras, principalmente as pequenas se enquadram nesse cenário. Nesse artigo utilizamos o exemplo de uma única gráfica, a Navio Serigrafia, mas podemos entender que se trata de um estudo de caso que pode ser generalizado, de modo que estima-se que existam muitos outros em situação semelhante.

Essa gráfica se enquadra no âmbito das indústrias criativas, conforme foi observado no início deste capítulo. É uma empresa que está localizada na ponta final da cadeia produtiva do design gráfico, sendo um fornecedor técnico da área do design. Dessa maneira, pode-se entender porque ela se encontra imersa no mundo da informalidade, esse mundo que se sustenta pela ausência de leis robustas para essas empresas se enquadrarem corretamente no âmbito legal.

É possível verificar também que essas empresas não estão muito preocupadas em sair do mundo da informalidade, e continuam a desenvolver seu trabalho sem grandes obstáculos, e sem muito esclarecimento a cerca do impacto negativo e distorções que isso gera para todo um setor produtivo.

\section{Conclusão}

Com este artigo pretende-se descrever o exemplo de uma empresa brasileira, da categoria de micro-empresa, que, para sobreviver em meio a tantos entraves como os encargos da lei brasileira, se encaixa no ambíguo mundo da informalidade. Neste mundo quase tudo é possível em relação a leis, quase tudo é permitido.

Tem-se como sugestão para futuros trabalhos aprofundar um parecer sobre a comparação entre as duas realidades que se impõem à indústria gráfica brasileira. Tem-se, por um lado, o mundo da informalidade, no qual se encontram as micro e pequenas empresas, e que procurou-se exemplificar e tangibilizar neste artigo.

E do outro lado, o mundo da formalidade, onde encontram-se as grandes gráficas, que só conseguem produzir mantendo-se dentro da legalidade. São gráficas que até possuem a certificação $\mathrm{FSC}^{\circledR}$, certificado dados a empresas cujos trabalhos são produzidos com papel proveniente de florestas de replantio e manejo sustentável. Esse certificado torna possível o trabalho de uma gráfica com grandes empresas nacionais e multinacionais, como também a sua participação em licitações. Neste nicho não há lugar para a informalidade.

Assim, vislumbra-se estas duas realidades contrastantes do setor gráfico brasileiro, a realidade informal e a realidade formal. A informalidade pode até facilitar, num certo sentido, a perpetuação dos pequenos, porém também ajuda a torná-los invisíveis. 


\section{Referências}

BENDASSOLLI, P. F.; PINA e CUNHA, M.; KIRSCHBAUM, C.; WOOD Jr., T. Indústrias Criativas: Definição, limites e possibilidades. RAE, São Paulo, v.49, n.1, jan./mar. 2009. Disponível em: http://www.scielo.br/pdf/rae/v49n1/v49n1a03.pdf. Acesso em: 11 jun. 2017.

BRASIL. RECEITA FEDERAL. Informações Gerais sobre o CNPJ. 2014. Disponível em: $<$ http://idg.receita.fazenda.gov.br/orientacao/tributaria/cadastros/cadastro-nacional-de-pessoasjuridicas-cnpj/informacoes-gerais-sobre-o-cnpj>. Acesso em: 20 dez. 2017.

DESIGNERS BRASILEIROS. A importância do registro de marca para o design. Disponível em: <https://designersbrasileiros.com.br/registro-de-marca/>. Acesso em: 22 dez. 2017.

FEDERAÇÃO DAS INDÚSTRIAS DO ESTADO DO RIO DE JANEIRO (Rio de Janeiro). Diagnósticos e Mapeamentos Setoriais: Retrato Setorial Gráfico e Editorial. Rio de Janeiro: Firjan, 2017. Disponível em: <http://www.firjan.com.br/publicacoes/publicacoes-de-economia/retrato-setorialgrafico.htm>. Acesso em: 20 dez. 2017.

FSC. Tipos de certificados FSC. Disponível em: <https://br.fsc.org/pt-br/certificao/tipos-decertificados>. Acesso em: 25 dez. 2017.

INPI (Brasil). Instituto Nacional da Propriedade Industrial (Org.). A criação de uma marca: Uma introdução às marcas de produtos e srviços para as pequenas e médias empresas. Rio de Janeiro: Inpi, 2013. Disponível em:

<http://www.inpi.gov.br/sobre/arquivos/01_cartilhamarcas_21_01_2014_0.pdf>. Acesso em: 22 dez. 2017.

LUIZ RICARDO CAVALCANTE (Brasil). Instituto de Pesquisa Econômica Aplicada (Ipea). Texto para Discussão: Ambiente de Negócios, Investimento e Produtividade. Rio de Janeiro, 1990. Disponível em: <http://www.ipea.gov.br/portal/images/stories/PDFs/TDs/td_2130f.pdf>. Acesso em: 19 dez. 2017.

MAGNA EMPRESA JURÍDICA JÚNIOR. CNPJ, qual a sua importância e qual a sua necessidade. Disponível em: <http://www.magnaempresajunior.com.br/2017/08/24/cnpj-qual-a-suaimportancia-qual-a-sua-necessidade/>. Acesso em: 22 dez. 2017.

PEDUTI SOCIEDADE DE ADVOGADOS. Propriedade Intelectual, Marcas. Disponível em: <http://peduti.com.br/area-da-atuacao/marcas-e-patentes/>. Acesso em: 22 dez. 2017.

REIS, A. C. F. Economia da cultura e desenvolvimento sustentável: o caleidoscópio da cultura. Baureri, SP: Manole, 2007. 